\title{
Central Europe as a Postcolonial Region
}

Moritz Csáky: Gedächtnis Zentraleuropas. Kulturelle und literarische Projektionen auf eine Region. Wien: Böhlau Verlag, 2019. 392 pp.

\section{Tamás Lénárt}

Institute of Hungarian Literature and Cultural Studies, Eötvös Loránd University Budapest, Múzeum krt. 4/A, 1088 Budapest, Hungary; lenart.tamas@btk.elte.hu

Moritz Csáky's volume, Gedächtnis Zentraleuropas welcomes the reader with a dramatic cover: next to the map and imperial symbols of the Austro-Hungarian Monarchy, there is a large allegorical female figure from a 1900s postcard, dressed in black and yellow-the colours of the Imperial House of Habsburg. The facial expression of the figure is enigmatic; as if she glimpsed back but without satisfaction; her glance is coquettish, perhaps gloomy or resigned, the pose is-as today's viewer would say-pathetic, moderated and empty, still very impactful. The cover revokes Walter Benjamin's concept of the "angel of history", also discussed in the book, one of the best-known articulations of the importance and challenges of history and memory in the 20th century. Gedächtnis Zentraleuropas is essentially a book about the history of the Austro-Hungarian Empire, however, considering its structure and methodology, it is far more challenging to pinpoint its genre; it mostly seeks an answer to how it is possible and worth thinking and talking about history in the light of humanities' contemporary findings and questions, that is after postcolonial theory, and after the cultural and the spatial turn.

The focus of the book is not a country but a region, "Central Europe"-Csáky carefully differentiates it from the "Mitteleuropa" label that has had such a decisive role primarily in German self-identification. Therefore, the attributes that are in the foreground in Csáky's work draft a different concept. The summary of the premiss of Gedächtnis Zentraleuropas is that Central Europe is an area inhabited by different ethnic groups with different languages and identities, and the area's unity, cultural identity, and historical memory arise from or lead back to this complex, multi-ethnic, and multilingual structure. The volume examines this thesis: on the one hand, approaching the topic from multiple angles sets the issue in the wider context of social science and the theory of history, on the other hand, through the introduction 
of numerous characteristic literary texts and publications from the region confirms the assumption, as well as points to key junctures and sub-questions. Last but not least, the book shows how Central Europe's 19th and 20th century dilemmas can serve as lessons for Europe's current social and political debates.

The book is divided into eight chapters. Its approach and style are a pronouncedly uniform, easy to follow essay-style that reads the text discussed attentively, but does not try to 'solve' it. Instead, it draws an elaborate picture of the historical context in which the particular text was written, or rather which the text reflects on. The first chapter is an extensive introduction to clarify the book's theoretical position. Already at this point, Csáky refers to writers: the Central Europe-concept is elucidated by the views of Milan Kundera and Danilo Kiš. In their works, essays, and interviews, both authors describe a multi-lingual and multi-cultural, pluralistic, and as such, a hard to grasp yet decisive experience. The following subchapter refines this introduction by citing the Slovakian literary theorist Peter Zajac, claiming that the concept is not just about comparing cultures (or literatures) that exist side by side, but also about continuous and mutual interferences, about the experience of heteronomy and hybridity. By using these terms, Csáky embeds the examination of Central Europe's history into the perspective-structure of postcolonial theory. After these considerations, the introduction essentially turns into a series of mini-essays, each of them exhibiting a distinctive aspect of the concept: amongst other issues, the situation of the Jewry (as an ethnic group with mixed identity and different levels of assimilation); the etymological differentiation of the terms "Central Europe" and "Mitteleuropa"; the role of the Habsburg Empire; the question of the Hungarian language and national identity; and in general the impossibility of the concept of "national" culture; the idiosyncrasies of the situation between "East" and "West"; the region's interpretation as "little Europe"; the role of big cities in the formation of cultural pluralities; the significance of borders and the border-situation; the traces of the heteronomy of the region's culture in the history of Vienna-related music, the region's gastronomy, and last but not least, in the philosophical efforts of the Vienna Circle of Logical Empiricism.

The book's most frequently cited authors: the above-mentioned Kundera and Kiš; Robert Musil; Hugo von Hoffmannsthal; Joseph Roth and others appear in the introduction, where the theoretical foundation of the concept is laid. Besides the postcolonial theory hallmarked by Homi K. Bhabha (introducing the terms "hybrid identities" and "mimicry"), Yuri M. Lotman's semiotic theory of culture is given an emphatic role: the concept of the "semiosphere", and the significance of borders, transitions, and translation in this context. There is a mini essay on Georg Simmel's sociological theory of the stranger, as well as on the connections of memory and identity following Friedrich Nietzsche's and Walter Benjamin's theories of history. 
It is perhaps apparent even from this short and incomplete list that the introduction is not following a linear train of thought but tends to catalogue numerous additional problems and examples of the same concept, almost repeating themselves, in order to guide the reader in new directions, offering a broad variety of topics. The author confidently delves into the cultural history of the region's larger and smaller ethnic groups, as well as into the literature, music, philosophy, and gastronomy of the era, while handling the relevant theoretical and philosophical texts in an elegant manner.

The introduction is followed by four chapters, each dedicated to the study of a relevant text. Besides the two literary works, Franz Kafka's Beim Bau der chinesischen Mauer [The Great Wall of China] (II) and Joseph Roth's novel Das falsche Gewicht [The False Weight] (IV), two political, historical essays, Hermann Bahr's Austriaca (III) and Miroslav Krleža's work Illyricum sacrum (V) are analysed in separate chapters. Kafka's short story is read by Csáky as an allegory where the plot taking place at the time of the construction of the Great Wall corresponds to the political and social situation of the Austro-Hungarian Monarchy, whose regional centre, Prague, was Kafka's residence. The monumentality, the identity-forming effect, and the adversities of the construction of the Wall described in the story represent the impossibility of the centralization of the divided Chinese Empire, a pattern that can be interpreted as a keen-eyed and ingenious analysis of the social reality of Franz Joseph's Dual Monarchy. Based on the same logic, Joseph Roth's novel becomes a postcolonial fable exemplifying the mutuality of the relationship between centre and periphery: the controller representing the centre arrives at the periphery to investigate the irregularities, i.e., he intends to colonise the land. The novel presents how the new environment "sucks the controller in", how he assimilates, how the direction of colonisation turns around, and-as a result-so does the hierarchy of the centre-periphery model. Austriaca by Hermann Bahr-one of the most frequently cited authors in other chapters of the book, as Csáky is one of the editors of Bahr's writings - is essentially the practical and political articulation of a similar notion of de-hierarchisation; it critiques the Habsburg Monarchy by referencing the decentralization, and suggests a federalist model, a "Vielvölkerstaat" dominated by Slavic nations, corresponding to the population distribution. In other words, from Vienna's perspective, Bahr advocates for pluralism in a cultural and political sense, eliminating the core centre-periphery structure. Krleža's work from 1944 is an overview of the history of the Southern Slavic region, focusing on the mixed and contradictory nature of the self-identities of the Southern Slavic nations. In its own time, Krleža's emphasis on the role of historical traumas and hybrid identities when examining the history of the region must have had a different significance, however the text is a great opportunity for Csáky to clarify the role of historical consciousness in the formation of national identity, as well as to appreciate the Illyricum sacrum as the prefiguration of the pluralist model developed in the book. 
Following the four analytical chapters, there are two thematic chapters, one (VI) focusing on multilingualism in the Central European region, the other (VII) addressing the experience of the foreign and foreignness, and dealing with the formation of strangeness and with the reflections on this experience. The methodology and style of the book stay uniform. Chapters VI and VII are fundamentally built on literary or journalistic texts, which analyse, contextualise, and bind together into a coherent argumentation. The 'protagonists' of Chapter VI are Fritz Mautner, a multi-lingual philosopher from Bohemia, writing on language criticism, Franz Kafka reflecting on the roles of Yiddish and German as a writing language, Robert Musil discussing the topic of multilingualism in his novel The Man Without Qualities, Prague-born Rainer Maria Rilke and his assumptions on the languages of the Monarchy, and finally Jan Evangelista Purkyně, who published a pamphlet entitled Austria polyglotta in the defence of multilingualism in 1867. Through these and other examples the chapter presents the issue from as many angles as possible: the mother tongue and multilingualism are the foundations of individual and social identity, and they define culture as a communicational space or "semiosphere"; multilingualism was present in the background of the "crisis of language" marking the beginning of modernity, and had a huge influence on the philosophy of the language-sceptical Vienna Circle. In fact, nearly everything we know about modernity can be connected to the formations of linguistic diversity that emerged in Central Europe-this is what makes Chapter VI perhaps the most intriguing, most complex section of the book, the one evoking the most ideas that point towards future considerations.

Chapter VII deals with strangeness, highlighting one aspect of the premiss of the introduction. This section unfolds the topic with the help of the novels of Wilma von Vukelich, an author of Jewish descent, who immigrated from Mohács in Hungary, and lived in Osijek (Eszék in Hungarian) in Croatia, the short story Pogrom by Franz Werfel, and Robert Michel's texts representing a "soldier-writer's" narrative about Bosnia. Based on these, the topic of strangeness in the multi-ethnical monarchy unfolds via two thematic nodes: the situation of Jews, and "Habsburg orientalism" witnessed in descriptions of Bosnia and other, more remote regions. The closing chapter is more of an outlook than a summary, as it deepens the idea raised in the introduction, and glimpses at the conclusions gained from the historical examination of the Central European region from a contemporary point of view. Considering the complexity of Central Europe, a hundred years ago and the challenges of this hybrid culture, we might better understand today's Europe, the Europe of cultural diversity, as well as its challenges.

Overall, Csáky's work provides more of a wide panorama and less of an analysis of individual phenomena; as an example, the strongly differing opinions of Kafka and 
Rilke on multilingualism leave plenty of room for drawing further consequences. The book in general deals with literary texts, writers, and journalists; the presentation focuses on outlining the wider cultural and historical context and does not pursue the further literary and linguistic analysis of the texts. For instance, it does not address the role of allegories in Kafka's short stories, neither does it deal with the significance of Joseph Roth's ironical linguistic formations and other rhetorical and poetic structures. As a result, we can perhaps conclude that Das Gedächtnis Zentraleuropas is not about literary history and the philosophy of language, but rather about the regional and social history of the Dual Monarchy, with a special focus on its cultural diversity and multilingualism.

To conclude, Das Gedächtnis Zentraleuropas is a conceptual piece of work that efficiently applies the discourse of postcolonial theory to the author's area of research, the history of 19th and 20th century Central Europe. From a different angle, however, it is a synthesis collecting the most significant results of a rich life of research. Unfolding on the pages are the history of the region's nations, urbanism, literature, music, gastronomy, and memorial culture, drawing attention to intriguing, often unexpected connections, parallels, and conjunctions. The book is a genuine journey into the truly diverse, often hard to understand, peculiar, "unheimlich" or weird depths of Central Europe. 